\title{
Enseki Far-Infrared Sandbath: Its Basic and Future Therapeutic Possibilities
}

\author{
Yoshinori Aragane* \\ Togenkai Dermatology, Japan
}

Submission: March 30, 2020; Published: April 13, 2020

*Corresponding author: Yoshinori Aragane, Togenkai Dermatology, Japan

\begin{abstract}
It is well known that heat therapies, including Finnish sauna, have various health advantages and thus long been performed worldwide since ancient time. Recently, we focused on physical nature of ceramic, which emit far-infrared ray upon heating. Accordingly, we developed ceramic beads, whose electromagnetic wave profiles are almost identical to those of a black body, a perfect far-infrared radiator. A bathtub, equipped with computerized hot water circulation system, was first filled with the ceramic beads. Those beads in the bathtub were heated by circulating hot water at $50^{\circ} \mathrm{C}$ which was drained out thereafter, and then a bather was laid in a supine position and covered with the heated ceramic beads in depth of 5-10 cm except the facial-cranial region and sandbathed for 15 minutes. In this minireview, we briefly overview the physiological response to the far-infrared sandbathing and the immune impacts. Finally, some discussion was done for the logical and mechanical basics and future therapeutic possibilities.
\end{abstract}

Keywords: Enseki Sandbath; Far-Infrared Ray; Heat Therapy; Immune Impacts

Abbreviations: CD40L: CD40 Ligand; eNOS: Endothelial Nitric Oxide Synthase; FIR: Far-Infrared, HSP: Heat Shock Protein; IL: Interleukin; TNF: Tumor Necrosis Factor; TRP: Transient Receptor Potential; PBMC: Peripheral Blood Mononuclear Cells; PHA: Phytohemagglutinin, PLZF: Promyelocytic Leukemia Zinc Finger Protein

\section{Introduction}

It has widely been recognized that sauna bathing is generally used to maintain mental as well as physical health [1]. Not only in the Scandinavian regions and northern Europe, sauna bathing has long been used as one of therapeutic modalities for hundred years, even in far-east countries, i.e. oriental style sauna of Korea and Ibusuki sandbath, Kagoshima, Japan. Finnish steam sauna is a representative in this context, however, there are several other ways of sauna, such as dry-heat sauna, infrared sauna and far-infrared (FIR) sauna [2]. Developing energy sources, emitters and other photo-technologies, various ways of FIR sauna have been upgraded so far [3]. The classification of the International Commission on Illumination has three subdivisions for the infrared (IR) radiation, which are composed of near-IR (IR-A, wavelength ranges of $700 \mathrm{~nm}-1400 \mathrm{~nm}$ ), midIR (IR-B, wavelength ranges of $1400 \mathrm{~nm}-3000 \mathrm{~nm}$ ) and far-IR (IR-C, wavelength ranges of $3000 \mathrm{~nm}-1 \mathrm{~mm}$ ). In terms of tissue penetration when exposed to human skin, deepest penetration is obtained by near IR (approximately $5 \mathrm{~mm}$ ) [4]. FIR exposure only results in superficial penetration [5], which, however, has various clinical advantages [6,7].

In general, FIR saunas heat to $40-60{ }^{\circ} \mathrm{C}$ and utilize 120 $\mathrm{V}$ infrared elements which irradiate electromagnetic waves with a wavelength of around $10 \mu \mathrm{m}$ [8]. There are two ways of FIR irradiators applicable for patients' use as follows. First, an FIR emitter consisted of electrified ceramic plates is located approximately $20 \mathrm{~cm}$ above a bather, which steadily increase skin temperature [9]. The second is an FIR dry sauna in which light is used to create heat and directly irradiate the target (indeed, skin) [10]. In 'Enseki' sandbath, a novel FIR sauna system our team reported recently, ceramic beads were filled in a bathtub equipped with computerized hot water circulating system and heated at up to $50{ }^{\circ} \mathrm{C}[11]$.

Immediately after temperature of ceramic beads reached sufficiently, the hot-water was drained-out, and a bather was laid in a supine position and was completely covered with depth of 5-10 cm (except for a head and a face) by ceramic beads like 
sandbathing. Based on the biological nature of the ceramic beads which emit FIR ray when heated at around $50{ }^{\circ} \mathrm{C}$, the Enseki method was conducted as FIR bathing. By repetitively conducting microbacteriological analyses, it was found that at any step of the procedures or on any parts of the circulation systems no pathogens were grown [11]. To analyze its safety for human use, various physiological parameters were checked in bathers before, during and after the sandbathing, including blood pressure, heart rates, oral temperature, body weight and blood viscosity, all of which were only affected in the similar extent with other types of sauna. Consequently, it appeared that Enseki method was, at least, no negative impact on human health. Biochemical analysis was also performed including blood glucose, HbA1c, uric acid, lactate, fatty acid and others, demonstrating no abnormal score [11]. Finally, results of questionnaires demonstrated that $90 \%$ of the participants answered the comfort and wished to further repeat the bathing [11].

\section{Discussion}

When electromagnetic waves transfer heat to human body, three possible routes exist, i.e. 1) direct heat transfer, 2) convection, and 3) radiation. Since FIR does not necessarily require transfer media by energy transfer, convection may be involved only in a minor route. Again, majority of ceramic beads did not contact skin surface except for those locating just outside of the skin and thus were not entirely capable of direct energy transfer. Hence, radiation of FIR from heated ceramic beads is likely to be the major route which is assisted by direct energy transfer. Enseki sandbathing may influence immune cascades as evidenced as follows. First, the numbers of peripheral leukocytes were increased after the sandbathing [12]. However, the proportion of each leukocyte subsets (granulocytes, lymphocytes, eosinophils and basophils) was not altered. Similarly, it was previously reported that sauna bathing led to the increase in the number of white blood cells among athletes but not in non-athletes13. In that study, they concluded as 'sauna bathing stimulated the immune system to a higher degree in the group of athletes compared to the untrained subjects'. As we did not enroll athletes in our studies, the Enseki sandbathing might lead more effectively to the increase in peripheral leukocyte numbers.

Second, the ratio of $\mathrm{CD}^{+} / \mathrm{CD}^{+} \mathrm{T}$ cells was significantly increased $[12,13]$. The similar finding was previously reported that the thermal bathing as well as radon hot spring bathing highered CD4/CD8 ratio in bathers [14]. Thus it might be probable that this is rather common phenomenon among thermal therapies. Previously, it was reported that inverted CD4/CD8 ratio was associated during aging and thus may reflect immune senescence [15]. In terms of senescence, it was reported that aging is accompanied with decline in acquired cell-mediated immunity, leading to the decrease in acquired humoral immunity [16].
Since aging is continuous and progressive processes, the sandbathing-induced increment of CD4/CD8 ratio might be interpreted as forced immune rejuvenation. The biological significance of this event should further be explored. Third, the Enseki sandbathing led to production of interleukin (IL)- 6 and tumor necrosis factor (TNF)- $\alpha$ in vivo in sera of human subjects [12]. Although we do not know the biological significance yet, one can interpret that Enseki-sandbathing-affected events, at least, may activate immune cascade.

Forth, Enseki sandbathing may lead to PHA-stimulated proliferation of $\mathrm{T}$ cells [12]. Collectively, these findings indicate that sandbathing induced 1) release of cytokine, IL- 6 and TNF- $\alpha$ and 2) enhanced proliferation of T cells in PHA-stimulated PBMC. One can speculate that Enseki sandbathing may activate immune cascade including $\mathrm{T}$ cell proliferation, which might possibly be of therapeutic significance. To date molecular mechanisms underlying the biological effects of FIR rays are still unclear. As previously reported, FIR mediates its biological effects on target cells via thermal and non-thermal ways. In terms of thermal effects, FIR-signals first may activate thermoregulators on the skin cells. For instance, it has been reported that transient receptor potential (TRP) channels in skin are crucial to maintain internal temperature balance and thermal homeostasis [17]. Interestingly, different TRP may be activated depending upon degrees of temperature stimulation. It implies that, when compared with traditional Finnish sauna, relatively lower temperature setting of the Enseki sandbathing might activate different TRP channels, leading to different clinical effects. Furthermore, it also has nicely been shown that using snake systems TRP channels may work as sensors for infrared detection [18]. In our system, radiated FIR rays might activate some TRP channels other than those affected by high temperature Finnish sauna. This might be attributed to physiologic effects that are characteristic for the Enseki sandbathing.

By contrast, it was reported that one of possible candidates representing non-thermal effects is FIR-induced nitric oxide (NO) in endothelial cells [19]. Extending that speculation, Hsu et al. has reported that FIR may induce nuclear translocation of promyelocystic leukemia zinc finger protein (PLZF) in the endothelial cells of human umbilical vein, which was independent of a thermal effect [20]. In that paper, they demonstrated that FIR exposure induced the nuclear translocation of PLZF which up-regulated phosphatidyl inositol-3 kinase to activate Akt, and then activated endothelial NO synthase (eNOS) to induce NO generation. Finally, they concluded that through a PLZF-mediated pathway, FIR may be a potential therapeutic modality to maintain vascular endothelial health and function [20]. Based on their observation, it might be possible to speculate that the Enseki sandbathing also may activate such signal transduction pathway 
via thermal as well as non-thermal ways. Not only via non-thermal pathways, but thermal effects are also known to be involved in activation of eNOS [21].

It was known that heat shock proteins are capable of induction of immune systems such as proliferation of $\mathrm{T}$ cells and production of cytokines such as IL- 6 and TNF- $\alpha$, and thus plays a proinflammatory role when released as soluble forms. Wang et al. reported that soluble HSPs activated antigen presenting DC via induction of surface CD40L and IL-15R which further activated $\mathrm{T}$ cells via CD40/CD40L- and IL-15/IL-15R-systems [22]. Interestingly, sHSP may induce effective anti-tumor immunity possibly via induction of $\mathrm{CD}^{+}$cells producing granzyme $\mathrm{B}$ independently of target cells, while it induced the anti-tumor ability of $\mathrm{CD}^{+}$cells which demanded the presence of target tumor cells. Furthermore, it was reported that balneotherapy with hot water at $38-40{ }^{\circ} \mathrm{C}$ induced production of serum HSP70 [23]. It might be possible to speculate that Enseki sandbathing via inducing soluble HSPs may possess immune modulatory capability. This remains elucidated and is future target of further researches.

The Enseki sandbathing led to the decrease in blood triglyceride and blood fatty acid peroxide, while the increase was observed in blood free fatty acid [11]. This phenomenon might be induced by the facilitation of degradation from triglyceride to free fatty acids via activation of lipoprotein lipase. Hence, through the activation of metabolisms, the Enseki sandbathing induces triglyceride metabolisms by activated lipoprotein lipase. So when adequate aerobic exercise is combined, the Enseki procedure might well be useful for weight control. By use of Enseki sandbathing we performed laser Doppler study demonstrating dilatation of radial artery by $24 \%$ and increase in circulating blood volume of the radial artery at 2.43 times. Furthermore, acceleration of the flow speed by approximately 1.7 times [11].

The similar tendency was also observed in popliteal artery. These data indicates that the Enseki procedure temporarily dilated radial as well as popliteal arteries, leading to the increase in the peripheral circulating blood volume. Together with previous observations emphasizing usefulness of heat therapy on cardiovascular diseases [24-27], those findings suggest that the Enseki bathing might be possibly one of useful therapeutic modalities for cardiovascular disorders. One of self-explanatory effects on heat therapy is the increase in body temperature. Indeed, thermographic analysis demonstrated the relatively rapid increase in body surface temperature. The Enseki sandbathing may flexibly control skin circulation as well, so it might be the effective tool to activate function and proliferation of skin constituents, such as dermal fibroblasts capable of collagen production. So repetitive Enseki sandbathing might be a better tool for skin rejuvenation.

\section{Conclusion}

Although more detailed validation of the effects at molecular levels is necessary, we conclude that this is worth being a new FIRtherapeutic modality, by which Enseki sandbathing might give us better contribution on our life in physical, immunological, mental as well as rejuvenation contexts.

\section{Acknowledgement}

The author is heartfully grateful to Professor Hideaki Higashino, a former director, Department of Pharmacology, Kindai University School of Medicine, Osakasayama, Japan for his continuous help, suggestions and guidance to complete this work. The author is also thankful to Ms. Masako Aragane for her secretarial assistance.

\section{References}

1. Brenke R (2015) Das Potenzial der Sauna im Rahmen der Prävention - eine Übersicht neuerer Erkenntnisse. Forsch Komplementmed 22(5): 320-325.

2. Crinnion WJ (2011) Sauna as a valuable clinical tool for cardiovascular, autoimmune, toxicant- induced and other chronic health problems. Altern Med Rev 16(3): 215-225.

3. Beever R (2009) Far-infrared saunas for treatment of cardiovascular risk factors: summary of published evidence. Can Fam Physician 55 (7): 691-696.

4. Ai X, Mu J, Xing B (2016) Recent Advances of Light-Mediated Theranostics. Theranostics 6(13): 2439-2457.

5. Vatansever F, Hamblin HR (2012) Far infrared radiation (FIR): its biological effects and medical applications. Photonics Lasers Med 4: 255-266.

6. Shui S, Wang X, Chiang JY, Zheng L (2015) Far-infrared therapy for cardiovascular, autoimmune, and other chronic health problems: A systematic review. Exp Biol Med (Maywood) 240(10): 1257-1265.

7. Lin CC, Yang WC (2009) Prognostic factors influencing the patency of hemodialysis vascular access: literature review and novel therapeutic modality by far infrared therapy. J Chin Med Assoc 72(3): 109-116.

8. Mero A, Tornberg J, Mäntykoski M, Puurtinen R (2015) Effects of farinfrared sauna bathing on recovery from strength and endurance training sessions in men. Springerplus 4: 321.

9. Lin CC, Chang CF, Lai MY, Chen TW, Lee PC, et al (2007) Far-infrared therapy: a novel treatment to improve access blood flow and unassisted patency of arteriovenous fistula in hemodialysis patients. J Am Soc Nephrol 18(3): 985-992.

10. Munemoto T, Soejima Y, Masuda A, Nakabeppu Y, Tei C (2017) Increase in the regional cerebral blood flow following Waon therapy in patients with chronic fatigue syndrome: A pilot study. Intern Med 56(14): 18171824.

11. Aragane Y, Higashino H (2019) The Enseki sandbath: A novel, safe and effective far-infrared bathing procedure for health. Photodermatol Photoimmunol Photomed 35(1): 31-39. 
12. Aragane Y, Higashino H (2020) Activation of T-cell proliferation by Enseki sandbath. Photodermatol Photoimmunol Photomed 36(1): 6869.

13. Pilch W, Pokora I , Szyguła Z, Pałka T, Pilch P, et al. (2013) Effect of a single Finnish sauna session on white blood cell profile and cortisol levels in athletes and non-athletes. J Hum Kinet 39: 127-135.

14. Yamaoka K, Mitsunobu F, Hanamoto K, Shibuya K, Mori D, et al. (2004) Biochemical comparison between radon effects and thermal effects on humans in radon hot spring therapy. J Rad Res 45(1): 83-88.

15. Muller GC, Gottlieb MG, Luz Correa B, Gomes Filho I, Moresco RN, et al. (2015) The inverted CD4:CD8 ratio is associated with gender-related changes in oxidative stress during aging. Cell Immunol 296(2):149154.

16. Aspinall R (2003) Age-related changes in the function of $T$ cells. Microsc Res Tech 62(6): 508-513.

17. Hsu WL, Yoshioka T (2015) Role of TRP channels in the induction of heat shock protein (Hsps) by heating skin. Biophysics 11: 25-32.

18. Gracheva EO, Ingolia NT, Kelly YM, Cordero-Morales JF, Hollopeter G, et al. (2010) Molecular basis of infrared detection by snakes. Nature 464 (7291): 1006-1011.

19. Lin CC, Chang CF, Lai MY, Chen TW, Lee PC, et al. (2007) Far-infrared therapy: A novel treatment to improve access blood flow and unassisted patency of arteriovenous fistula in hemodialysis patients. J Am Soc Nephrol 18(3): 985-992.

20. Hsu YH, Chen YC, Chen TH, Sue YM, Cheng TH, et al. (2012) Far-infrared therapy induces the nuclear translocation of PLZF which inhibits VEGF-induced proliferation in human umbilical vein endothelial cells. PLoS One 7(1): e30674.

21. Ikeda Y, Biro S, Kamogawa Y, Yoshifuku S, Eto H, et al. (2006) Repeated sauna therapy increases arterial endothelial nitric oxide synthase expression and nitric oxide production in cardiomyopathic hamsters. Circ J 69 (6): 722-729.

22. Wang Y, Seidl T, Whittall T, Babaahmady K, Lehner T (2010) Stressactivated dendritic cells interact with $\mathrm{CD} 4{ }^{+} \mathrm{T}$ cells to elicit homeostatic memory. Eur J Immunol 40(6): 1628-1638.

23. Ustyol EA, Karaarslan F, Bekpinar S, Ozkuk K, Erdogan N (2017) Effects of balneotherapy on serum levels of shingosine-1-phosphate in patients with osteoarthritis. Altern Ther Health Med 23(6): 10-14.

24. Ernst E, Strziga P, Schmidlechner C, Magyarosy I (1986) Sauna effects on hemorheology and other variables. Arch Phys Med Rehabil 67(8): 526-529.

25. Krause M, Ludwig MS, Heck TG, Takahashi HK (2015) Heat shock proteins and heat therapy for type 2 diabetes: pros and cons. Curr Opin Clin Nutr Metab Care 18(4): 374-380.

26. Brunt VE, Howard MJ, Francisco MA, Ely BR, Minson CT (2016) Passive heat therapy improves endothelial function, arterial stiffness and blood pressure in sedentary humans. J Physiol 594(18): 5329-5324.

27. Miyata M, Tei C (2010) Waon therapy for cardiovascular disease -Innovative therapy for the 21st century- (2010). Circ J 74(4): 617-621.

\section{Your next submission with Juniper Publishers} will reach you the below assets

- Quality Editorial service

- Swift Peer Review

- Reprints availability

- E-prints Service

- Manuscript Podcast for convenient understanding

- Global attainment for your research

- Manuscript accessibility in different formats

( Pdf, E-pub, Full Text, Audio)

- Unceasing customer service

\section{Track the below URL for one-step submission}

https://juniperpublishers.com/online-submission.php 